\title{
On Strong Convergence by the Hybrid Method for Equilibrium and Fixed Point Problems for an Inifnite Family of Asymptotically Nonexpansive Mappings
}

\author{
Gang Cai and Chang song Hu \\ Department of Mathematics, Hubei Normal University, Huangshi 435002, China \\ Correspondence should be addressed to Gang Cai, caigang-aaaa@163.com and \\ Chang song $\mathrm{Hu}$, huchang1004@yahoo.com.cn
}

Received 17 April 2009; Accepted 9 July 2009

Recommended by Tomonari Suzuki

We introduce two modifications of the Mann iteration, by using the hybrid methods, for equilibrium and fixed point problems for an infinite family of asymptotically nonexpansive mappings in a Hilbert space. Then, we prove that such two sequences converge strongly to a common element of the set of solutions of an equilibrium problem and the set of common fixed points of an infinite family of asymptotically nonexpansive mappings. Our results improve and extend the results announced by many others.

Copyright @ 2009 G. Cai and C. S. Hu. This is an open access article distributed under the Creative Commons Attribution License, which permits unrestricted use, distribution, and reproduction in any medium, provided the original work is properly cited.

\section{Introduction}

Let $C$ be a nonempty closed convex subset of a Hilbert space $H$. A mapping $T: C \rightarrow C$ is said to be nonexpansive if for all $x, y \in C$ we have $\|T x-T y\| \leq\|x-y\|$. It is said to be asymptotically nonexpansive [1] if there exists a sequence $\left\{k_{n}\right\}$ with $k_{n} \geq 1$ and $\lim _{n \rightarrow \infty} k_{n}=1$ such that $\left\|T^{n} x-T^{n} y\right\| \leq k_{n}\|x-y\|$ for all integers $n \geq 1$ and for all $x, y \in C$. The set of fixed points of $T$ is denoted by $F(T)$.

Let $\phi: C \times C \rightarrow R$ be a bifunction, where $R$ is the set of real number. The equilibrium problem for the function $\phi$ is to find a point $x \in C$ such that

$$
\phi(x, y) \geq 0 \quad \forall y \in C .
$$

The set of solutions of (1.1) is denoted by $E P(\phi)$. In 2005, Combettes and Hirstoaga [2] introduced an iterative scheme of finding the best approximation to the initial data when $E P(\phi)$ is nonempty, and they also proved a strong convergence theorem. 
For a bifunction $\phi: C \times C \rightarrow R$ and a nonlinear mapping $A: C \rightarrow H$, we consider the following equilibrium problem:

$$
\text { Find } z \in C \text { such that } \phi(z, y)+\langle A z, y-z\rangle \geq 0, \quad \forall y \in C \text {. }
$$

The set of such that $z \in C$ is denoted by $E P$, that is,

$$
E P=\{z \in C: \phi(z, y)+\langle A z, y-z\rangle \geq 0, \forall y \in C\}
$$

In the case of $A=0, E P=E P(\phi)$. In the case of $\phi \equiv 0, E P$ is denoted by $V I(C, A)$. The problem (1.2) is very general in the sense that it includes, as special cases, some optimization problems, variational inequalities, minimax problems, the Nash equilibrium problem in noncooperative games, and others (see, e.g., [3, 4]).

Recall that a mapping $A: C \rightarrow H$ is called monotone if

$$
\langle A u-A v, u-v\rangle \geq 0, \quad \forall u, v \in C .
$$

A mapping $A$ of $C$ into $H$ is called $\alpha$-inverse strongly monotone, see [5-7], if there exists a positive real number $\alpha$ such that

$$
\langle x-y, A x-A y\rangle \geq \alpha\|A x-A y\|^{2}
$$

for all $x, y \in C$. It is obvious that any $\alpha$-inverse strongly monotone mapping $A$ is monotone and Lipschitz continuous.

Construction of fixed points of nonexpansive mappings and asymptotically nonexpansive mappings is an important subject in nonlinear operator theory and its applications, in particular, in image recovery and signal processing (see, e.g., [1, 8-10]). Fixed point iteration processes for nonexpansive mappings and asymptotically nonexpansive mappings in Hilbert spaces and Banach spaces including Mann [11] and Ishikawa [12] iteration processes have been studied extensively by many authors to solve nonlinear operator equations as well as variational inequalities; see, for example, [11-13]. However, Mann and Ishikawa iteration processes have only weak convergence even in Hilbert spaces (see, e.g., [11, 12]).

Some attempts to modify the Mann iteration method so that strong convergence is guaranteed have recently been made. In 2003, Nakajo and Takahashi [14] proposed the following modification of the Mann iteration method for a nonexpansive mapping $T$ in a Hilbert space $H$ :

$$
\begin{gathered}
x_{0} \in C \text { chosen arbitrarily, } \\
y_{n}=\alpha_{n} x_{n}+\left(1-\alpha_{n}\right) T x_{n}, \\
C_{n}=\left\{v \in C:\left\|y_{n}-v\right\| \leq\left\|x_{n}-v\right\|\right\}, \\
Q_{n}=\left\{v \in C:\left\langle x_{n}-v, x_{0}-x_{n}\right\rangle \geq 0\right\}, \\
x_{n+1}=P_{C_{n} \cap Q_{n}} x_{0},
\end{gathered}
$$


where $P_{C}$ denotes the metric projection from $H$ onto a closed convex subset $C$ of $H$. They proved that if the sequence $\left\{\alpha_{n}\right\}$ bounded above from one, then $\left\{x_{n}\right\}$ defined by (1.6) converges strongly to $P_{F(T)} x_{0}$.

Recently, Kim and $\mathrm{Xu}$ [15] adapted the iteration (1.6) to an asymptotically nonexpansive mapping in a Hilbert space $H$ :

$$
\begin{gathered}
x_{0} \in C \text { chosen arbitrarily, } \\
y_{n}=\alpha_{n} x_{n}+\left(1-\alpha_{n}\right) T^{n} x_{n} \\
C_{n}=\left\{v \in C:\left\|y_{n}-v\right\|^{2} \leq\left\|x_{n}-v\right\|^{2}+\theta_{n}\right\}, \\
Q_{n}=\left\{v \in C:\left\langle x_{n}-v, x_{0}-x_{n}\right\rangle \geq 0\right\}, \\
x_{n+1}=P_{C_{n} \cap Q_{n}} x_{0},
\end{gathered}
$$

where $\theta_{n}=\left(1-\alpha_{n}\right)\left(k_{n}^{2}-1\right)(\operatorname{diam} C)^{2} \rightarrow 0$, as $n \rightarrow \infty$. They proved that if $\alpha_{n} \leq a$ for all $n$ and for some $0<a<1$, then the sequence $\left\{x_{n}\right\}$ generated by (1.7) converges strongly to $P_{\text {Fix }(T)}\left(x_{0}\right)$.

Very recently, Inchan and Plubtieng [16] introduced the modified Ishikawa iteration process by the shrinking hybrid method [17] for two asymptotically nonexpansive mappings $S$ and $T$, with $C$ a closed convex bounded subset of a Hilbert space $H$. For $C_{1}=C$ and $x_{1}=P_{C_{1}} x_{0}$, define $\left\{x_{n}\right\}$ as follows:

$$
\begin{gathered}
y_{n}=\alpha_{n} x_{n}+\left(1-\alpha_{n}\right) T^{n} z_{n}, \\
z_{n}=\beta_{n} x_{n}+\left(1-\beta_{n}\right) S^{n} x_{n}, \\
C_{n+1}=\left\{v \in C_{n}:\left\|y_{n}-v\right\|^{2} \leq\left\|x_{n}-v\right\|^{2}+\theta_{n}\right\}, \\
x_{n+1}=P_{C_{n+1}} x_{0}, \quad n \in N,
\end{gathered}
$$

where $\theta_{n}=\left(1-\alpha_{n}\right)\left[\left(t_{n}^{2}-1\right)+\left(1-\beta_{n}\right) t_{n}^{2}\left(s_{n}^{2}-1\right)\right](\operatorname{diam} C)^{2} \rightarrow 0$, as $n \rightarrow \infty$ and $0 \leq \alpha_{n} \leq a<1$ and $0<b \leq \beta_{n} \leq c<1$ for all $n \in N$. They proved that the sequence $\left\{x_{n}\right\}$ generated by (1.8) converges strongly to a common fixed point of two asymptotically nonexpansive mappings $S$ and $T$.

Zegeye and Shahzad [18] established the following hybrid iteration process for a finite family of asymptotically nonexpansive mappings in a Hilbert space $H$ :

$$
\begin{gathered}
x_{0} \in C \text { chosen arbitrarily, } \\
y_{n}=\alpha_{n 0} x_{n}+\alpha_{n 1} T_{1}^{n} x_{n}+\alpha_{n 2} T_{2}^{n} x_{n}+\alpha_{n 3} T_{3}^{n} x_{n}+\cdots+\alpha_{n r} T_{r}^{n} x_{n}, \\
C_{n}=\left\{v \in C:\left\|y_{n}-v\right\|^{2} \leq\left\|x_{n}-v\right\|^{2}+\theta_{n}\right\}, \\
Q_{n}=\left\{v \in C:\left\langle x_{n}-v, x_{0}-x_{n}\right\rangle \geq 0\right\}, \\
x_{n+1}=P_{C_{n} \cap Q_{n}}\left(x_{0}\right),
\end{gathered}
$$


where $\theta_{n}=\left[\left(k_{n 1}^{2}-1\right) \alpha_{n 1}+\left(k_{n 2}^{2}-1\right) \alpha_{n 2}+\cdots+\left(k_{n r}^{2}-1\right) \alpha_{n r}\right](\operatorname{diam} C)^{2} \rightarrow 0$, as $n \rightarrow \infty$. Under suitable conditions strong convergence theorem is proved which extends and improves the corresponding results of Nakajo and Takahashi [14] and Kim and $\mathrm{Xu}$ [15].

On the other hand, for finding a common element of $E P(\phi) \cap F(S)$, Tada and Takahashi [19] introduced the following iterative scheme by the hybrid method in a Hilbert space: $x_{0}=$ $x \in H$ and let

$$
\begin{gathered}
u_{n} \in C \text { such that } \phi\left(u_{n}, y\right)+\frac{1}{r_{n}}\left\langle y-u_{n}, u_{n}-x_{n}\right\rangle \geq 0, \quad \forall y \in C, \\
w_{n}=\left(1-\alpha_{n}\right) x_{n}+\alpha_{n} S u_{n} \\
C_{n}=\left\{z \in H:\left\|w_{n}-z\right\| \leq\left\|x_{n}-z\right\|\right\} \\
Q_{n}=\left\{z \in C:\left\langle x_{n}-z, x_{0}-x_{n}\right\rangle \geq 0\right\} \\
x_{n+1}=P_{C_{n} \cap Q_{n}} x_{0}
\end{gathered}
$$

for every $n \in N \cup\{0\}$, where $\left\{\alpha_{n}\right\} \subset[a, b]$ for some $a, b \in(0,1)$ and $\left\{r_{n}\right\} \subset(0, \infty)$ satisfies $\lim \inf _{n \rightarrow \infty} r_{n}>0$. Further, they proved that $\left\{x_{n}\right\}$ and $\left\{u_{n}\right\}$ converge strongly to $z \in E P(\phi) \cap$ $F(S)$, where $z=P_{E P(\phi) \cap F(S)} x_{0}$.

Inspired and motivated by the above facts, it is the purpose of this paper to introduce the Mann iteration process for finding a common element of the set of common fixed points of an infinite family of asymptotically nonexpansive mappings and the set of solutions of an equilibrium problem. Then we prove some strong convergence theorems which extend and improve the corresponding results of Tada and Takahashi [19], Inchan and Plubtieng [16], Zegeye and Shahazad [18], and many others.

\section{Preliminaries}

We will use the following notations:

(1) " $\longrightarrow$ " for weak convergence and " $\rightarrow$ " for strong convergence;

(2) $w_{\omega}\left(x_{n}\right)=\left\{x: \exists x_{n_{j}} \rightarrow x\right\}$ denotes the weak $\omega$-limit set of $\left\{x_{n}\right\}$.

Let $H$ be a real Hilbert space. It is well known that

$$
\|x-y\|^{2}=\|x\|^{2}-\|y\|^{2}-2\langle x-y, y\rangle
$$

for all $x, y \in H$.

It is well known that $H$ satisfies Opial's condition [20], that is, for any sequence $\left\{x_{n}\right\}$ with $x_{n} \rightarrow x$, the inequality

$$
\liminf _{n \rightarrow \infty}\left\|x_{n}-x\right\|<\liminf _{n \rightarrow \infty}\left\|x_{n}-y\right\|
$$

holds for every $y \in H$ with $y \neq x$. Hilbert space $H$ satisfies the Kadec-Klee property [21, 22], that is, for any sequence $\left\{x_{n}\right\}$ with $x_{n} \rightarrow x$ and $\left\|x_{n}\right\| \rightarrow\|x\|$ together imply $\left\|x_{n}-x\right\| \rightarrow 0$. 
We need some facts and tools in a real Hilbert space $H$ which are listed as follows.

Lemma 2.1 ([23]). Let $T$ be an asymptotically nonexpansive mapping defined on a nonempty bounded closed convex subset $C$ of a Hilbert space $H$. If $\left\{x_{n}\right\}$ is a sequence in $C$ such that $x_{n} \rightarrow z$ and $T x_{n}-x_{n} \rightarrow 0$, then $z \in F(T)$.

Lemma 2.2 ([24]). Let $C$ be a nonempty closed convex subset of $H$ and also give a real number $a \in R$. The set $D:=\left\{v \in C:\|y-v\|^{2} \leq\|x-v\|^{2}+\langle z, v\rangle+a\right\}$ is convex and closed.

Lemma 2.3 ([22]). Let $C$ be a nonempty closed convex subset of $H$, and let $P_{C}$ be the (metric or nearest) projection from $H$ onto $C$ (i.e., $P_{C} x$ is the only point in $C$ such that $\left\|x-P_{C} x\right\|=\inf \{\|x-z\|$ : $\forall z \in C\})$. Given $x \in H$ and $z \in C$. Then $z=P_{C} x$ if and only if it holds the relation:

$$
\langle x-z, y-z\rangle \leq 0, \quad \forall y \in C
$$

For solving the equilibrium problem, let us assume that the bifunction $\phi$ satisfies the following conditions (see [3]):

(A1) $\phi(x, x)=0$ for all $x \in C$;

(A2) $\phi$ is monotone, that is, $\phi(x, y)+\phi(y, x) \leq 0$ for any $x, y \in C$;

(A3) $\phi$ is upper-hemicontinuous, that is, for each $x, y, z \in C$

$$
\limsup _{t \rightarrow 0^{+}} \phi(t z+(1-t) x, y) \leq \phi(x, y)
$$

(A4) $\phi(x, \cdot)$ is convex and weakly lower semicontinuous for each $x \in C$.

The following lemma appears implicity in [3].

Lemma 2.4 ([3]). Let $C$ be a nonempty closed convex subset of $H$, and let $\phi$ be a bifunction of $C \times C$ into $R$ satisfying (A1)-(A4). Let $r>0$ and $x \in H$. Then, there exists $z \in C$ such that

$$
\phi(z, y)+\frac{1}{r}\langle y-z, z-x\rangle \geq 0 \quad \forall y \in C .
$$

The following lemma was also given in [2].

Lemma 2.5 ([2]). Assume that $\phi: C \times C \rightarrow R$ satisfies (A1)-(A4). For $r>0$ and $x \in H$, define a mapping $T_{r}: H \rightarrow C$ as follows:

$$
T_{r}(x)=\left\{z \in C: \phi(z, y)+\frac{1}{r}\langle y-z, z-x\rangle \geq 0 \forall y \in C\right\}
$$


for all $x \in H$. Then, the following holds

(1) $T_{r}$ is single-valued;

(2) $T_{r}$ is firmly nonexpansive, that is, for any $x, y \in H,\left\|T_{r} x-T_{r} y\right\|^{2} \leq\left\langle T_{r} x-T_{r} y, x-y\right\rangle$.

This implies that $\left\|T_{r} x-T_{r} y\right\| \leq\|x-y\|, \forall x, y \in H$, that is, $T_{r}$ is a nonexpansive mapping:

(3) $F\left(T_{r}\right)=E P(\phi), \forall r>0$;

(4) $E P(\phi)$ is a closed and convex set.

Definition 2.6 (see [25]). Let $C$ be a nonempty closed convex subset of $H$. Let $\left\{S_{m}\right\}$ be a family of asymptotically nonexpansive mappings of $C$ into itself, and let $\left\{\beta_{n, k}: n, k \in N, 1 \leq k \leq n\right\}$ be a sequence of real numbers such that $0 \leq \beta_{i, j} \leq 1$ for every $i, j \in N$ with $i \geq j$. For any $n \geq 1$ define a mapping $W_{n}: C \rightarrow C$ as follows:

$$
\begin{gathered}
U_{n, n}=\beta_{n, n} S_{n}^{n}+\left(1-\beta_{n, n}\right) I, \\
U_{n, n-1}=\beta_{n, n-1} S_{n-1}^{n} U_{n, n}+\left(1-\beta_{n, n-1}\right) I, \\
\vdots \\
U_{n, k}=\beta_{n, k} S_{k}^{n} U_{n, k+1}+\left(1-\beta_{n, k}\right) I, \\
\vdots \\
U_{n, 2}=\beta_{n, 2} S_{2}^{n} U_{n, 3}+\left(1-\beta_{n, 2}\right) I \\
W_{n}=U_{n, 1}=\beta_{n, 1} S_{1}^{n} U_{n, 2}+\left(1-\beta_{n, 1}\right) I .
\end{gathered}
$$

Such a mapping $W_{n}$ is called the modified $W$-mapping generated by $S_{n}, S_{n-1}, \ldots, S_{1}$ and $\beta_{n, n}, \beta_{n, n-1}, \ldots, \beta_{n, 2}, \beta_{n, 1}$.

Lemma 2.7 ([10, Lemma 4.1]). Let $C$ be a nonempty closed convex subset of $H$. Let $\left\{S_{m}\right\}$ be a family of asymptotically nonexpansive mappings of $C$ into itself with Lipschitz constants $\left\{t_{m, n}\right\}$, that is, $\left\|S_{m}^{n} x-S_{m}^{n} y\right\| \leq t_{m, n}\|x-y\|$ (for all $m, n \in N$, for all $x, y \in C$ ) such that $F:=\cap_{i=1}^{\infty} F\left(S_{i}\right) \neq \emptyset$, and let $\left\{\beta_{n, k}: n, k \in N, 1 \leq k \leq n\right\}$ be a sequence of real numbers with $0<a \leq \beta_{n, 1} \leq 1$ for all $n \in N$ and $0<b \leq \beta_{n, i} \leq c<1$ for every $n \in N$ and $i=2, \ldots, n$ for some $a, b, c \in(0,1)$. Let $W_{n}$ be the modified $W$-mapping generated by $S_{n}, S_{n-1}, \ldots, S_{1}$ and $\beta_{n, n}, \beta_{n, n-1}, \ldots, \beta_{n, 2}, \beta_{n, 1}$. Let $r_{n, k}=\left\{\beta_{n, k}\left(t_{k, n}^{2}-1\right)+\beta_{n, k} \beta_{n, k+1} t_{k, n}^{2}\left(t_{k+1, n}^{2}-1\right)+\cdots+\beta_{n, k} \beta_{n, k+1} \cdots \beta_{n, n-1} t_{k, n}^{2} t_{k+1, n}^{2} \cdots t_{n-2, n}^{2}\left(t_{n-1, n}^{2}-\right.\right.$ 1) $\left.+\beta_{n, k} \beta_{n, k+1} \cdots \beta_{n, n} t_{k, n}^{2} t_{k+1, n}^{2} \cdots t_{n-1, n}^{2}\left(t_{n, n}^{2}-1\right)\right\}$ for every $n \in N$ and $k=1,2, \ldots, n$. Then, the followings hold:

(i) $\left\|W_{n} x-z\right\|^{2} \leq\left(1+r_{n, 1}\right)\|x-z\|^{2}$ for all $n \in N, x \in C$ and $z \in \cap_{i=1}^{n} F\left(S_{i}\right)$;

(ii) if $C$ is bounded and $\lim _{n \rightarrow \infty} r_{n, 1}=0$, for every sequence $\left\{z_{n}\right\}$ in $C$,

$$
\lim _{n \rightarrow \infty}\left\|z_{n+1}-z_{n}\right\|=0, \quad \lim _{n \rightarrow \infty} z_{n}-W_{n} z_{n}=0 \quad \text { imply } w_{\omega}\left(z_{n}\right) \subset F ;
$$

(iii) if $\lim _{n \rightarrow \infty} r_{n, 1}=0, F=\cap_{i=1}^{\infty} F\left(W_{n}\right)$ and $F$ is closed convex. 
Lemma 2.8 ([10, Lemma 4.4]). Let $C$ be a nonempty closed convex subset of $H$. Let $\left\{S_{m}\right\}$ be a family of asymptotically nonexpansive mappings of $C$ into itself with Lipschitz constants $\left\{t_{m, n}\right\}$, that is, $\left\|S_{m}^{n} x-S_{m}^{n} y\right\| \leq t_{m, n}\|x-y\|$ (for all $m, n \in N$, for all $x, y \in C$ ) such that $F:=\cap_{i=1}^{\infty} F\left(S_{i}\right) \neq \emptyset$. Let $T_{n}=\sum_{k=1}^{n} \beta_{n, k} S_{k}^{n}$ for every $n \in N$, where $0 \leq \beta_{n, k} \leq 1$ for every $n=1,2,3, \ldots$ and $k=$ $1,2, \ldots, n$ with $\sum_{k=1}^{n} \beta_{n, k}=1$ for every $n \in N$ and $\lim _{n \rightarrow \infty} \beta_{n, k}>0$ for every $k \in N$, and let $r_{n}=\sum_{k=1}^{n} \beta_{n, k}\left(t_{k, n}^{2}-1\right)$ for every $n \in N$. Then, the following holds:

(i) $\left\|T_{n} x-z\right\|^{2} \leq\left(1+r_{n}\right)\|x-z\|^{2}$ for all $n \in N, x \in C$ and $z \in \cap_{i=1}^{n} F\left(S_{i}\right)$;

(ii) if $C$ is bounded and $\lim _{n \rightarrow \infty} r_{n}=0$, for every sequence $\left\{z_{n}\right\}$ in $C$,

$$
\lim _{n \rightarrow \infty}\left\|z_{n+1}-z_{n}\right\|=0, \quad \lim _{n \rightarrow \infty}\left\|z_{n}-T_{n} z_{n}\right\|=0 \quad \text { imply } w_{\omega}\left(z_{n}\right) \subset F
$$

(iii) if $\lim _{n \rightarrow \infty} r_{n}=0, F=\cap_{i=1}^{\infty} F\left(T_{n}\right)$ and $F$ is closed convex.

\section{Main Results}

In this section, we will introduce two iterative schemes by using hybrid approximation method for finding a common element of the set of common fixed points for a family of infinitely asymptotically nonexpansive mappings and the set of solutions of an equilibrium problem in Hilbert space. Then we show that the sequences converge strongly to a common element of the two sets.

Theorem 3.1. Let $C$ be a nonempty bounded closed convex subset of a real Hilbert space $H$, let $\phi: C \times$ $C \rightarrow R$ be a bifunction satisfying the conditions (A1)-(A4), let A be an $\alpha$-inverse strongly monotone mapping of $C$ into $H$, let $\left\{S_{m}\right\}$ be a family of asymptotically nonexpansive mappings of $C$ into itself with Lipschitz constants $\left\{t_{m, n}\right\}$, that is, $\left\|S_{m}^{n} x-S_{m}^{n} y\right\| \leq t_{m, n}\|x-y\|$ (for all $m, n \in N$, for all $x, y \in C$ ) such that $F \cap E P \neq \emptyset$, where $F:=\cap_{i=1}^{\infty} F\left(S_{i}\right)$, and let $\left\{\beta_{n, k}: n, k \in N, 1 \leq k \leq n\right\}$ be a sequence of real numbers with $0<a \leq \beta_{n, 1} \leq 1$ for all $n \in N$ and $0<b \leq \beta_{n, i} \leq c<1$ for every $n \in N$ and $i=2, \ldots, n$ for some $a, b, c \in(0,1)$. Let $W_{n}$ be the modified $W$-mapping generated by $S_{n}, S_{n-1}, \ldots, S_{1}$ and $\beta_{n, n}, \beta_{n, n-1}, \ldots, \beta_{n, 2}, \beta_{n, 1}$. Assume that $r_{n, k}=\left\{\beta_{n, k}\left(t_{k, n}^{2}-1\right)+\beta_{n, k} \beta_{n, k+1} t_{k, n}^{2}\left(t_{k+1, n}^{2}-1\right)+\cdots+\right.$ $\left.\beta_{n, k} \beta_{n, k+1} \cdots \beta_{n, n-1} t_{k, n}^{2} t_{k+1, n}^{2} \cdots t_{n-2, n}^{2}\left(t_{n-1, n}^{2}-1\right)+\beta_{n, k} \beta_{n, k+1} \cdots \beta_{n, n} t_{k, n}^{2} t_{k+1, n}^{2} \cdots t_{n-1, n}^{2}\left(t_{n, n}^{2}-1\right)\right\}$ for every $n \in N$ and $k=1,2, \ldots, n$ such that $\lim _{n \rightarrow \infty} r_{n, 1}=0$. Let $\left\{x_{n}\right\}$ and $\left\{u_{n}\right\}$ be sequences generated by the following algorithm:

$$
x_{0} \in C \text { chosen arbitrarily, }
$$

$$
\begin{gathered}
u_{n} \in C \text { such that } \phi\left(u_{n}, y\right)+\left\langle A x_{n}, y-u_{n}\right\rangle+\frac{1}{r_{n}}\left\langle y-u_{n}, u_{n}-x_{n}\right\rangle \geq 0, \quad \forall y \in C, \\
y_{n}=\alpha_{n} u_{n}+\left(1-\alpha_{n}\right) W_{n} u_{n}, \\
C_{n+1}=\left\{v \in C_{n}:\left\|y_{n}-v\right\|^{2} \leq\left\|x_{n}-v\right\|^{2}+\theta_{n}\right\}, \\
x_{n+1}=P_{C_{n+1}} x_{0}, \quad n \in N \cup\{0\},
\end{gathered}
$$

where $C_{0}=C$ and $\theta_{n}=\left(1-\alpha_{n}\right) r_{n, 1}(\operatorname{diam} C)^{2}$ and $0 \leq \alpha_{n} \leq d<1$ and $0<e \leq r_{n} \leq f<2 \alpha$. Then $\left\{x_{n}\right\}$ and $\left\{u_{n}\right\}$ converge strongly to $P_{F \cap E P}\left(x_{0}\right)$. 
Proof. We show first that the sequences $\left\{x_{n}\right\}$ and $\left\{u_{n}\right\}$ are well defined.

We observe that $C_{n}$ is closed and convex by Lemma 2.2. Next we show that $F \cap E P \subset C_{n}$ for all $n$. we prove first that $\left(I-r_{n} A\right)$ is nonexpansive. Let $x, y \in C$. Since $A$ is $\alpha$-inverse strongly monotone and $r_{n}<2 \alpha \forall n \in N$, we have

$$
\begin{aligned}
\left\|\left(I-r_{n} A\right) x-\left(I-r_{n} A\right) y\right\|^{2} & =\left\|x-y-r_{n}(A x-A y)\right\|^{2} \\
& =\|x-y\|^{2}-2 r_{n}\langle x-y, A x-A y\rangle+r_{n}^{2}\|A x-A y\|^{2} \\
& \leq\|x-y\|^{2}-2 \alpha r_{n}\|A x-A y\|^{2}+r_{n}^{2}\|A x-A y\|^{2} \\
& =\|x-y\|^{2}+r_{n}\left(r_{n}-2 \alpha\right)\|A x-A y\|^{2} \\
& \leq\|x-y\|^{2} .
\end{aligned}
$$

Thus $\left(I-r_{n}\right) A$ is nonexpansive.

Since

$$
\phi\left(u_{n}, y\right)+\left\langle A x_{n}, y-u_{n}\right\rangle+\frac{1}{r_{n}}\left\langle y-u_{n}, u_{n}-x_{n}\right\rangle \geq 0, \quad \forall y \in C,
$$

we obtain

$$
\phi\left(u_{n}, y\right)+\frac{1}{r_{n}}\left\langle y-u_{n}, u_{n}-\left(I-r_{n} A\right) x_{n}\right\rangle \geq 0, \quad \forall y \in C
$$

By Lemma 2.5, we have $u_{n}=T_{r_{n}}\left(x_{n}-r_{n} A x_{n}\right)$, for all $n \in N$.

Let $p \in F \cap E P$, it follows the definition of $E P$ that

$$
\phi(p, y)+\langle y-p, A p\rangle \geq 0, \quad \forall y \in C
$$

So,

$$
\phi(p, y)+\frac{1}{r_{n}}\left\langle y-p, p-\left(p-r_{n} A p\right)\right\rangle \geq 0, \quad \forall y \in C
$$

Again by Lemma 2.5, we have $p=T_{r_{n}}\left(p-r_{n} A p\right)$, for all $n \in N$.

Since $I-r_{n} A$ and $T_{r_{n}}$ are nonexpansive, one has

$$
\left\|u_{n}-p\right\| \leq\left\|T_{r_{n}}\left(x_{n}-r_{n} A x_{n}\right)-T_{r_{n}}\left(p-r_{n} A p\right)\right\| \leq\left\|x_{n}-p\right\|, \quad \forall n \geq 1
$$


Then using the convexity of $\|\cdot\|^{2}$ and Lemma 2.7 we obtain that

$$
\begin{aligned}
\left\|y_{n}-p\right\|^{2} & =\left\|\alpha_{n}\left(u_{n}-p\right)+\left(1-\alpha_{n}\right)\left(W_{n} u_{n}-p\right)\right\|^{2} \\
& \leq \alpha_{n}\left\|u_{n}-p\right\|^{2}+\left(1-\alpha_{n}\right)\left\|W_{n} u_{n}-p\right\|^{2} \\
& \leq \alpha_{n}\left\|u_{n}-p\right\|^{2}+\left(1-\alpha_{n}\right)\left(1+r_{n, 1}\right)\left\|u_{n}-p\right\|^{2} \\
& =\left\|u_{n}-p\right\|^{2}+\left(1-\alpha_{n}\right) r_{n, 1}\left\|u_{n}-p\right\|^{2} \\
& \leq\left\|u_{n}-p\right\|^{2}+\theta_{n} \\
& \leq\left\|x_{n}-p\right\|^{2}+\theta_{n} .
\end{aligned}
$$

So $p \in C_{n}$ for all $n$ and hence $F \cap E P \subset C_{n}$ for all $n$. This implies that $\left\{x_{n}\right\}$ is well defined. From Lemma 2.4, we know that $\left\{u_{n}\right\}$ is also well defined.

Next, we prove that $\left\|x_{n+1}-x_{n}\right\| \rightarrow 0,\left\|x_{n}-u_{n}\right\| \rightarrow 0,\left\|u_{n+1}-u_{n}\right\| \rightarrow 0,\left\|u_{n}-W_{n} u_{n}\right\| \rightarrow 0$, as $n \rightarrow \infty$.

It follows from $x_{n}=P_{C_{n}} x_{0}$ that

$$
\left\langle x_{0}-x_{n}, x_{n}-v\right\rangle \geq 0, \quad \text { for each } v \in F \cap E P \subset C_{n}, n \in N
$$

So, for $p \in F \cap E P$, we have

$$
\begin{aligned}
0 \leq\left\langle x_{0}-x_{n}, x_{n}-p\right\rangle & =-\left\langle x_{n}-x_{0}, x_{n}-x_{0}\right\rangle+\left\langle x_{0}-x_{n}, x_{0}-p\right\rangle \\
& \leq-\left\|x_{n}-x_{0}\right\|^{2}+\left\|x_{n}-x_{0}\right\|\left\|x_{0}-p\right\| .
\end{aligned}
$$

This implies that

$$
\left\|x_{n}-x_{0}\right\|^{2} \leq\left\|x_{n}-x_{0}\right\|\left\|x_{0}-p\right\|
$$

and hence

$$
\left\|x_{n}-x_{0}\right\| \leq\left\|x_{0}-p\right\|
$$

Since $C$ is bounded, then $\left\{x_{n}\right\}$ and $\left\{u_{n}\right\}$ are bounded.

From $x_{n}=P_{C_{n}} x_{0}$ and $x_{n+1}=P_{C_{n+1}} x_{0} \in C_{n+1} \subset C_{n}$, we have

$$
\left\langle x_{0}-x_{n}, x_{n}-x_{n+1}\right\rangle \geq 0 \quad \forall n \in N \text {. }
$$

So,

$$
\begin{aligned}
0 \leq\left\langle x_{0}-x_{n}, x_{n}-x_{n+1}\right\rangle & =-\left\langle x_{n}-x_{0}, x_{n}-x_{0}\right\rangle+\left\langle x_{0}-x_{n}, x_{0}-x_{n+1}\right\rangle \\
& \leq-\left\|x_{n}-x_{0}\right\|^{2}+\left\|x_{n}-x_{0}\right\|\left\|x_{0}-x_{n+1}\right\| .
\end{aligned}
$$


This implies that

$$
\left\|x_{n}-x_{0}\right\| \leq\left\|x_{n+1}-x_{0}\right\| \cdot \quad \forall n \in N
$$

Hence, $\left\{\left\|x_{n}-x_{0}\right\|\right\}$ is nodecreasing, and so $\lim _{n \rightarrow \infty}\left\|x_{n}-x_{0}\right\|$ exists.

Next, we can show that $\lim _{n \rightarrow \infty}\left\|x_{n}-x_{n+1}\right\|=0$. Indeed, From (2.1) and (3.13), we obtain

$$
\begin{aligned}
\left\|x_{n+1}-x_{n}\right\|^{2} & =\left\|\left(x_{n+1}-x_{0}\right)-\left(x_{n}-x_{0}\right)\right\|^{2} \\
& =\left\|x_{n+1}-x_{0}\right\|^{2}-\left\|x_{n}-x_{0}\right\|^{2}-2\left\langle x_{n+1}-x_{n}, x_{n}-x_{0}\right\rangle \\
& \leq\left\|x_{n+1}-x_{0}\right\|^{2}-\left\|x_{n}-x_{0}\right\|^{2} .
\end{aligned}
$$

Since $\lim _{n \rightarrow \infty}\left\|x_{n}-x_{0}\right\|$ exists, we have

$$
\lim _{n \rightarrow \infty}\left\|x_{n}-x_{n+1}\right\|=0
$$

On the other hand, it follows from $x_{n+1} \in C_{n+1}$ that

$$
\left\|y_{n}-x_{n+1}\right\|^{2} \leq\left\|x_{n}-x_{n+1}\right\|^{2}+\theta_{n} \longrightarrow 0, \quad \text { as } n \longrightarrow \infty .
$$

It follows that

$$
\left\|y_{n}-x_{n}\right\| \leq\left\|y_{n}-x_{n+1}\right\|+\left\|x_{n+1}-x_{n}\right\| \longrightarrow 0, \quad \text { as } n \longrightarrow \infty
$$

Next, we claim that $\lim _{n \rightarrow \infty}\left\|x_{n}-u_{n}\right\|=0$. Let $p \in F \cap E P$, it follows from (3.8) that

$$
\begin{aligned}
\left\|y_{n}-p\right\|^{2} & \leq\left\|u_{n}-p\right\|^{2}+\theta_{n} \\
& =\left\|T_{r_{n}}\left(I-r_{n} A\right) x_{n}-T_{r_{n}}\left(I-r_{n} A\right) p\right\|^{2}+\theta_{n} \\
& \leq\left\|x_{n}-p\right\|^{2}+r_{n}\left(r_{n}-2 \alpha\right)\left\|A x_{n}-A p\right\|^{2}+\theta_{n} .
\end{aligned}
$$

This implies that

$$
\begin{aligned}
e(2 \alpha-f)\left\|A x_{n}-A p\right\|^{2} & \leq\left\|x_{n}-p\right\|^{2}-\left\|y_{n}-p\right\|^{2}+\theta_{n} \\
& \leq\left\|x_{n}-y_{n}\right\|\left(\left\|x_{n}-p\right\|+\left\|y_{n}-p\right\|\right)+\theta_{n} .
\end{aligned}
$$

It follows from (3.19) that

$$
\lim _{n \rightarrow \infty}\left\|A x_{n}-A p\right\|=0
$$


From Lemma 2.5, one has

$$
\begin{aligned}
\left\|u_{n}-p\right\|^{2}= & \left\|T_{r_{n}}\left(I-r_{n} A\right) x_{n}-T_{r_{n}}\left(I-r_{n} A\right) p\right\|^{2} \\
\leq & \left\langle\left(x_{n}-r_{n} A x_{n}\right)-\left(p-r_{n} A p\right), u_{n}-p\right\rangle \\
= & \frac{1}{2}\left\{\left\|x_{n}-r_{n} A x_{n}-\left(p-r_{n} A p\right)\right\|^{2}+\left\|u_{n}-p\right\|^{2}\right. \\
& \left.\quad-\left\|x_{n}-r_{n} A x_{n}-\left(p-r_{n} A p\right)-\left(u_{n}-p\right)\right\|^{2}\right\} \\
\leq & \frac{1}{2}\left\{\left\|x_{n}-p\right\|^{2}+\left\|u_{n}-p\right\|^{2}-\left\|x_{n}-u_{n}-r_{n}\left(A x_{n}-A p\right)\right\|^{2}\right\} \\
= & \frac{1}{2}\left\{\left\|x_{n}-p\right\|^{2}+\left\|u_{n}-p\right\|^{2}-\left\|x_{n}-u_{n}\right\|^{2}\right. \\
& \left.+2 r_{n}\left\langle x_{n}-u_{n}, A x_{n}-A p\right\rangle-r_{n}^{2}\left\|A x_{n}-A p\right\|^{2}\right\} .
\end{aligned}
$$

This implies that

$$
\begin{aligned}
\left\|u_{n}-p\right\|^{2} & \leq\left\|x_{n}-p\right\|^{2}-\left\|x_{n}-u_{n}\right\|^{2}+2 r_{n}\left\langle x_{n}-u_{n}, A x_{n}-A p\right\rangle-r_{n}^{2}\left\|A x_{n}-A p\right\|^{2} \\
& \leq\left\|x_{n}-p\right\|^{2}-\left\|x_{n}-u_{n}\right\|^{2}+2 r_{n}\left\langle x_{n}-u_{n}, A x_{n}-A p\right\rangle \\
& \leq\left\|x_{n}-p\right\|^{2}-\left\|x_{n}-u_{n}\right\|^{2}+2 r_{n}\left\|x_{n}-u_{n}\right\|\left\|A x_{n}-A p\right\| .
\end{aligned}
$$

By (3.8), we have

$$
\left\|y_{n}-p\right\|^{2} \leq\left\|u_{n}-p\right\|^{2}+\theta_{n}
$$

Substituting (3.24) into (3.25), we obtain

$$
\left\|y_{n}-p\right\|^{2} \leq\left\|x_{n}-p\right\|^{2}-\left\|x_{n}-u_{n}\right\|^{2}+2 r_{n}\left\|x_{n}-u_{n}\right\|\left\|A x_{n}-A p\right\|+\theta_{n}
$$

which implies that

$$
\begin{aligned}
\left\|x_{n}-u_{n}\right\|^{2} & \leq\left\|x_{n}-p\right\|^{2}-\left\|y_{n}-p\right\|^{2}+2 r_{n}\left\|x_{n}-u_{n}\right\|\left\|A x_{n}-A p\right\|+\theta_{n} \\
& \leq\left\|x_{n}-y_{n}\right\|\left(\left\|x_{n}-p\right\|+\left\|y_{n}-p\right\|\right)+2 r_{n}\left\|x_{n}-u_{n}\right\|\left\|A x_{n}-A p\right\|+\theta_{n} .
\end{aligned}
$$

Noticing that $\lim _{n \rightarrow \infty}\left\|A x_{n}-A p\right\|=0$ and (3.19), it follows from (3.27) that

$$
\lim _{n \rightarrow \infty}\left\|u_{n}-x_{n}\right\|=0
$$


From (3.17) and (3.28), we have

$$
\left\|u_{n}-u_{n+1}\right\| \leq\left\|u_{n}-x_{n}\right\|+\left\|x_{n}-x_{n+1}\right\|+\left\|x_{n+1}-u_{n+1}\right\| \longrightarrow 0, \quad \text { as } n \longrightarrow \infty
$$

Similarly, from (3.19) and (3.28), one has

$$
\left\|y_{n}-u_{n}\right\| \leq\left\|y_{n}-x_{n}\right\|+\left\|x_{n}-u_{n}\right\| \longrightarrow 0, \quad \text { as } n \longrightarrow \infty .
$$

Noticing that the condition $0 \leq \alpha_{n} \leq d<1$, it follows that

$$
\left(1-\alpha_{n}\right)\left\|W_{n} u_{n}-u_{n}\right\|=\left\|y_{n}-u_{n}\right\|
$$

which implies that

$$
\left\|W_{n} u_{n}-u_{n}\right\|=\frac{\left\|y_{n}-u_{n}\right\|}{1-\alpha_{n}}<\frac{\left\|y_{n}-u_{n}\right\|}{1-d} \longrightarrow 0, \quad \text { as } n \longrightarrow \infty
$$

Next, we prove that there exists a subsequence $\left\{x_{n_{i}}\right\}$ of $\left\{x_{n}\right\}$ which converges weakly to $z$, where $z \in F \cap E P$.

Since $\left\{x_{n}\right\}$ is bounded and $C$ is closed, there exists a subsequence $\left\{x_{n_{i}}\right\}$ of $\left\{x_{n}\right\}$ which converges weakly to $z$, where $z \in C$. From (3.28), we have $u_{n_{i}} \rightarrow z$. Noticing (3.29) and (3.32), it follows from Lemma 2.7 that $z \in F$. Next we prove that $z \in E P$. Since $u_{n}=T_{r_{n}}\left(x_{n}-r_{n} A x_{n}\right)$, for any $y \in C$, we have

$$
\phi\left(u_{n}, y\right)+\left\langle A x_{n}, y-u_{n}\right\rangle+\frac{1}{r_{n}}\left\langle y-u_{n}, u_{n}-x_{n}\right\rangle \geq 0
$$

From (A2), one has

$$
\left\langle A x_{n}, y-u_{n}\right\rangle+\frac{1}{r_{n}}\left\langle y-u_{n}, u_{n}-x_{n}\right\rangle \geq \phi\left(y, u_{n}\right) .
$$

Replacing $n$ by $n_{i}$, we obtain

$$
\left\langle A x_{n_{i}}, y-u_{n_{i}}\right\rangle+\left\langle y-u_{n_{i}}, \frac{u_{n_{i}}-x_{n_{i}}}{r_{n_{i}}}\right\rangle \geq \phi\left(y, u_{n_{i}}\right)
$$

Put $z_{t}=t y+(1-t) z$ for all $t \in(0,1]$ and $y \in C$. Then, we have $z_{t} \in C$. So we have

$$
\begin{aligned}
\left\langle z_{t}-u_{n_{i}}, A z_{t}\right\rangle \geq & \left\langle z_{t}-u_{n_{i}}, A z_{t}\right\rangle-\left\langle A x_{n_{i}}, z_{t}-u_{n_{i}}\right\rangle-\left\langle z_{t}-u_{n_{i}}, \frac{u_{n_{i}}-x_{n_{i}}}{r_{n_{i}}}\right\rangle+\phi\left(z_{t}, u_{n_{i}}\right) \\
= & \left\langle z_{t}-u_{n_{i}}, A z_{t}-A u_{n_{i}}\right\rangle+\left\langle z_{t}-u_{n_{i}}, A u_{n_{i}}-A x_{n_{i}}\right\rangle \\
& -\left\langle z_{t}-u_{n_{i}}, \frac{u_{n_{i}}-x_{n_{i}}}{r_{n_{i}}}\right\rangle+\phi\left(z_{t}, u_{n_{i}}\right) .
\end{aligned}
$$


Since $\left\|u_{n_{i}}-x_{n_{i}}\right\| \rightarrow 0$, we have $\left\|A u_{n_{i}}-A x_{n_{i}}\right\| \rightarrow 0$. Further, from monotonicity of $A$, we have $\left\langle z_{t}-u_{n_{i}}, A z_{t}-A u_{n_{i}}\right\rangle \geq 0$. So, from (A4) we have

$$
\left\langle z_{t}-z, A z_{t}\right\rangle \geq \phi\left(z_{t}, z\right)
$$

as $i \rightarrow \infty$. From (A1) and (A4), we also have

$$
\begin{aligned}
0 & =\phi\left(z_{t}, z_{t}\right) \leq t \phi\left(z_{t}, y\right)+(1-t) \phi\left(z_{t}, z\right) \\
& \leq t \phi\left(z_{t}, y\right)+(1-t)\left\langle z_{t}-z, A z_{t}\right\rangle \\
& =t \phi\left(z_{t}, y\right)+(1-t) t\left\langle y-z, A z_{t}\right\rangle,
\end{aligned}
$$

and hence

$$
0 \leq \phi\left(z_{t}, y\right)+(1-t)\left\langle y-z, A z_{t}\right\rangle
$$

Letting $t \rightarrow 0$, we have, for each $y \in C$,

$$
0 \leq \phi(z, y)+\langle y-z, A z\rangle
$$

This implies that $z \in E P$. Therefore $z \in F \cap E P$.

Finally we show that $x_{n} \rightarrow z$, $u_{n} \rightarrow z$, where $z=P_{F \cap E P(\phi)}\left(x_{0}\right)$.

Putting $z^{\prime}=P_{F \cap E P}\left(x_{0}\right)$ and consider the sequence $\left\{x_{0}-x_{n_{i}}\right\}$. Then we have $x_{0}-x_{n_{i}} \rightarrow$ $x_{0}-z$ and by the weak lower semicontinuity of the norm and by the fact that $\left\|x_{0}-x_{n+1}\right\| \leq$ $\left\|x_{0}-z^{\prime}\right\|$ for all $n \geq 0$ which is implied by the fact that $x_{n+1}=P_{C_{n+1}}\left(x_{0}\right)$, we obtain

$$
\begin{aligned}
\left\|x_{0}-z^{\prime}\right\| & \leq\left\|x_{0}-z\right\| \\
& \leq \liminf _{i \rightarrow \infty}\left\|x_{0}-x_{n_{i}}\right\| \\
& \leq \limsup _{i \rightarrow \infty}\left\|x_{0}-x_{n_{i}}\right\| \\
& \leq\left\|x_{0}-z^{\prime}\right\| .
\end{aligned}
$$

This implies that $\left\|x_{0}-z^{\prime}\right\|=\left\|x_{0}-z\right\|$ (hence $z^{\prime}=z$ by the uniqueness of the nearest point projection of $x_{0}$ onto $F \cap E P$ ) and that

$$
\left\|x_{0}-x_{n_{i}}\right\| \longrightarrow\left\|x_{0}-z^{\prime}\right\|
$$

It follows that $x_{0}-x_{n_{i}} \rightarrow x_{0}-z^{\prime}$, and hence $x_{n_{i}} \rightarrow z^{\prime}$. Since $\left\{x_{n_{i}}\right\}$ is an arbitrary (weakly convergent) subsequence of $\left\{x_{n}\right\}$, we conclude that $x_{n} \rightarrow z^{\prime}$. From (3.28), we know that $u_{n} \rightarrow z^{\prime}$ also. This completes the proof of Theorem 3.1.

Theorem 3.2. Let $C$ be a nonempty bounded closed convex subset of a real Hilbert space $H$, let $\phi: C \times C \rightarrow R$ be a bifunction satisfying the conditions (A1)-(A4), let $A$ be an $\alpha$-inverse strongly 
monotone mapping of $C$ into $H$, and let $\left\{S_{m}\right\}$ be a family of asymptotically nonexpansive mappings of $C$ into itself with Lipschitz constants $\left\{t_{m, n}\right\}$, that is, $\left\|S_{m}^{n} x-S_{m}^{n} y\right\| \leq t_{m, n}\|x-y\|$ (for all $m, n \in$ $N$, for all $x, y \in C$ ) such that $F \cap E P \neq \emptyset$, where $F:=\cap_{i=1}^{\infty} F\left(S_{i}\right)$. Let $T_{n}=\sum_{k=1}^{n} \beta_{n, k} S_{k}^{n}$ for every $n \in N$, where $0 \leq \beta_{n, k} \leq 1$ for every $n=1,2,3, \ldots$ and $k=1,2, \ldots, n$ with $\sum_{k=1}^{n} \beta_{n, k}=1$ for each $n \in N$ and $\lim _{n \rightarrow \infty} \beta_{n, k}>0$ for every $k \in N$, and assume that $\gamma_{n}=\sum_{k=1}^{n} \beta_{n, k}\left(t_{k, n}^{2}-1\right)$ for every $n \in N$ such that $\lim _{n \rightarrow \infty} \gamma_{n}=0$. Let $\left\{x_{n}\right\}$ and $\left\{u_{n}\right\}$ be sequences generated by

$$
x_{0} \in C \text { chosen arbitrarily, }
$$

$$
\begin{gathered}
u_{n} \in C \text { such that } \phi\left(u_{n}, y\right)+\left\langle A x_{n}, y-u_{n}\right\rangle+\frac{1}{r_{n}}\left\langle y-u_{n}, u_{n}-x_{n}\right\rangle \geq 0, \quad \forall y \in C, \\
y_{n}=\alpha_{n} u_{n}+\left(1-\alpha_{n}\right) T_{n} u_{n}, \\
C_{n}=\left\{v \in C:\left\|y_{n}-v\right\|^{2} \leq\left\|x_{n}-v\right\|^{2}+\theta_{n}\right\}, \\
Q_{n}=\left\{v \in C:\left\langle x_{0}-x_{n}, x_{n}-v\right\rangle \geq 0\right\}, \\
x_{n+1}=P_{C_{n} \cap Q_{n}} x_{0}, n \in N \cup\{0\},
\end{gathered}
$$

where $\theta_{n}=\left(1-\alpha_{n}\right) \gamma_{n}(\operatorname{diam} C)^{2}$ and $0 \leq \alpha_{n} \leq d<1$ and $0<e \leq r_{n} \leq f<2 \alpha$. Then $\left\{x_{n}\right\}$ and $\left\{u_{n}\right\}$ converge strongly to $P_{F \cap E P}\left(x_{0}\right)$.

Proof. We divide the proof of Theorem 3.2 into four steps.

(i) We show first that the sequences $\left\{x_{n}\right\}$ and $\left\{u_{n}\right\}$ are well defined.

From the definition of $C_{n}$ and $Q_{n}$, it is obvious that $C_{n}$ is closed and $Q_{n}$ is closed and convex for each $n \in N \cup 0$. We prove that $C_{n}$ is convex. Since

$$
\left\|y_{n}-v\right\|^{2} \leq\left\|x_{n}-v\right\|^{2}+\theta_{n}
$$

is equivalent to

$$
2\left\langle x_{n}-y_{n}, v\right\rangle \leq\left\|x_{n}\right\|^{2}-\left\|y_{n}\right\|^{2}+\theta_{n}
$$

it follows that $C_{n}$ is convex. So, $C_{n} \cap Q_{n}$ is a closed convex subset of $H$ for any $n$.

Next, we show that $F \cap E P \subseteq C_{n}$. Indeed, let $p \in F \cap E P$, and let $\left\{T_{r_{n}}\right\}$ be a sequence of mappings defined as in Lemma 2.5. Similar to the proof of Theorem 3.1, we have

$$
\left\|u_{n}-p\right\| \leq\left\|x_{n}-p\right\|
$$


Fixed Point Theory and Applications

By virtue of the convexity of norm $\|\cdot\|^{2},(3.46)$, and Lemma 2.8 , we have

$$
\begin{aligned}
\left\|y_{n}-p\right\|^{2} & =\left\|\alpha_{n}\left(u_{n}-p\right)+\left(1-\alpha_{n}\right)\left(T_{n} u_{n}-p\right)\right\|^{2} \\
& \leq \alpha_{n}\left\|u_{n}-p\right\|^{2}+\left(1-\alpha_{n}\right)\left\|T_{n} u_{n}-p\right\|^{2} \\
& \leq \alpha_{n}\left\|u_{n}-p\right\|^{2}+\left(1-\alpha_{n}\right)\left(1+\gamma_{n}\right)\left\|u_{n}-p\right\|^{2} \\
& =\left\|u_{n}-p\right\|^{2}+\left(1-\alpha_{n}\right) \gamma_{n}\left\|u_{n}-p\right\|^{2} \\
& \leq\left\|u_{n}-p\right\|^{2}+\theta_{n} \\
& \leq\left\|x_{n}-p\right\|^{2}+\theta_{n} .
\end{aligned}
$$

Therefore, $p \in C_{n}$ for all $n$.

Next, we prove that $F \cap E P \subseteq Q_{n}$, for all $n \geq 0$. For $n=0$, we have $F \cap E P \subseteq C=Q_{0}$. Assume that $F \cap E P \subseteq Q_{n-1}$. Since $x_{n}$ is the projection of $x_{0}$ onto $C_{n-1} \cap Q_{n-1}$, by Lemma 2.3, we have

$$
\left\langle x_{0}-x_{n}, x_{n}-v\right\rangle \geq 0, \quad \forall v \in C_{n-1} \cap Q_{n-1} .
$$

In particular, we have

$$
\left\langle x_{0}-x_{n}, x_{n}-p\right\rangle \geq 0
$$

for each $p \in F \cap E P$ and hence $p \in Q_{n}$. Hence $F \cap E P \subset Q_{n}$, for all $n \geq 0$. Therefore, we obtain that

$$
F \cap E P \subseteq C_{n} \cap Q_{n}, \quad \forall n \geq 0 .
$$

This implies that $\left\{x_{n}\right\}$ is well defined. From Lemma 2.4, we know that $\left\{u_{n}\right\}$ is also well defined.

(ii) We prove that $\left\|x_{n+1}-x_{n}\right\| \rightarrow 0,\left\|x_{n}-u_{n}\right\| \rightarrow 0,\left\|u_{n+1}-u_{n}\right\| \rightarrow 0,\left\|u_{n}-T_{n} u_{n}\right\| \rightarrow 0$, as $n \rightarrow \infty$.

Since $F \cap E P$ is a nonempty closed convex subset of $H$, there exists a unique $z^{\prime} \in F \cap E P$ such that $z^{\prime}=P_{F \cap E P} x_{0}$.

From $x_{n+1}=P_{C_{n} \cap Q_{n}} x_{0}$, we have

$$
\left\|x_{n+1}-x_{0}\right\| \leq\left\|v-x_{0}\right\| \quad \forall v \in C_{n} \cap Q_{n}, \forall n \in N \cup\{0\} .
$$

Since $z^{\prime} \in F \cap E P \subset C_{n} \cap Q_{n}$, we have

$$
\left\|x_{n+1}-x_{0}\right\| \leq\left\|z^{\prime}-x_{0}\right\| \quad \forall n \in N \cup\{0\}
$$


Since $C$ is bounded, we have $\left\{x_{n}\right\},\left\{u_{n}\right\}$, and $\left\{y_{n}\right\}$ are bounded. From the definition of $Q_{n}$, we have $x_{n}=P_{Q_{n}} x_{0}$, which together with the fact that $x_{n+1} \in C_{n} \cap Q_{n} \subset Q_{n}$ implies that

$$
\left\|x_{0}-x_{n}\right\| \leq\left\|x_{0}-x_{n+1}\right\|, \quad\left\langle x_{0}-x_{n}, x_{n+1}-x_{n}\right\rangle \leq 0 .
$$

This shows that the sequence $\left\{\left\|x_{n}-x_{0}\right\|\right\}$ is nondecreasing. So, $\lim _{n \rightarrow \infty}\left\|x_{n}-x_{0}\right\|$ exists.

It follows from (2.1) and (3.53) that

$$
\begin{aligned}
\left\|x_{n+1}-x_{n}\right\|^{2} & =\left\|\left(x_{n+1}-x_{0}\right)-\left(x_{n}-x_{0}\right)\right\|^{2} \\
& =\left\|x_{n+1}-x_{0}\right\|^{2}-\left\|x_{n}-x_{0}\right\|^{2}-2\left\langle x_{n+1}-x_{n}, x_{n}-x_{0}\right\rangle \\
& \leq\left\|x_{n+1}-x_{0}\right\|^{2}-\left\|x_{n}-x_{0}\right\|^{2} .
\end{aligned}
$$

Noticing that $\lim _{n \rightarrow \infty}\left\|x_{n}-x_{0}\right\|$ exists, this implies that

$$
\lim _{n \rightarrow \infty}\left\|x_{n}-x_{n+1}\right\|=0
$$

Since $x_{n+1} \in C_{n}$, we have

$$
\left\|y_{n}-x_{n+1}\right\|^{2} \leq\left\|x_{n}-x_{n+1}\right\|^{2}+\theta_{n}
$$

So, we have $\lim _{n \rightarrow \infty}\left\|y_{n}-x_{n+1}\right\|=0$. It follows that

$$
\left\|y_{n}-x_{n}\right\| \leq\left\|y_{n}-x_{n+1}\right\|+\left\|x_{n+1}-x_{n}\right\| \longrightarrow 0, \quad \text { as } n \longrightarrow \infty
$$

Similar to the proof of Theorem 3.1, we have

$$
\lim _{n \rightarrow \infty}\left\|x_{n}-u_{n}\right\|=0
$$

From (3.55) and (3.58), we have

$$
\left\|u_{n}-u_{n+1}\right\| \leq\left\|u_{n}-x_{n}\right\|+\left\|x_{n}-x_{n+1}\right\|+\left\|x_{n+1}-u_{n+1}\right\| \longrightarrow 0, \quad \text { as } n \longrightarrow \infty \text {. }
$$

Similarly, from (3.57) and (3.58), one has

$$
\left\|y_{n}-u_{n}\right\| \leq\left\|y_{n}-x_{n}\right\|+\left\|x_{n}-u_{n}\right\| \longrightarrow 0, \quad \text { as } n \longrightarrow \infty
$$

Noticing the condition $0 \leq \alpha_{n} \leq d<1$, it follows that

$$
\left(1-\alpha_{n}\right)\left\|T_{n} u_{n}-u_{n}\right\|=\left\|y_{n}-u_{n}\right\|
$$


which implies that

$$
\left\|T_{n} u_{n}-u_{n}\right\|=\frac{\left\|y_{n}-u_{n}\right\|}{1-\alpha_{n}}<\frac{\left\|y_{n}-u_{n}\right\|}{1-d} \longrightarrow 0, \quad \text { as } n \longrightarrow \infty
$$

(iii) We prove that there exists a subsequence $\left\{x_{n_{i}}\right\}$ of $\left\{x_{n}\right\}$ which converges weakly to $z$, where $z \in F \cap E P$.

Since $\left\{x_{n}\right\}$ is bounded and $C$ is closed, there exists a subsequence $\left\{x_{n_{i}}\right\}$ of $\left\{x_{n}\right\}$ which converges weakly to $z$, where $z \in C$. From (3.58), we have $u_{n_{i}} \rightarrow z$. Noticing (3.59) and (3.62), it follows from Lemma 2.8 that $z \in F$. By using the same method as in the proof of Theorem 3.1, we easily obtain that $z \in E P$.

(iv) Finally we show that $x_{n} \rightarrow z, u_{n} \rightarrow z$, where $z=P_{F \cap E P}\left(x_{0}\right)$.

Since $x_{n}=P_{Q_{n}} x_{0}$ and $z \in F \cap E P \subset Q_{n}$, we have

$$
\left\|x_{n}-x_{0}\right\| \leq\left\|z-x_{0}\right\|
$$

It follows from $z^{\prime}=P_{F \cap E P} x_{0}$ and the weak lower-semicontinuity of the norm that

$$
\left\|z^{\prime}-x_{0}\right\| \leq\left\|z-x_{0}\right\| \leq \liminf _{i \rightarrow \infty}\left\|x_{n_{i}}-x_{0}\right\| \leq \limsup _{i \rightarrow \infty}\left\|x_{n_{i}}-x_{0}\right\| \leq\left\|z^{\prime}-x_{0}\right\| .
$$

Thus, we obtain that $\lim _{i \rightarrow \infty}\left\|x_{n_{i}}-x_{0}\right\|=\left\|z-x_{0}\right\|=\left\|z^{\prime}-x_{0}\right\|$. Using the Kadec-Klee property of $H$, we obtain that

$$
\lim _{i \rightarrow \infty} x_{n_{i}}=z=z^{\prime}
$$

Since $\left\{x_{n_{i}}\right\}$ is an arbitrary subsequence of $\left\{x_{n}\right\}$, we conclude that $\left\{x_{n}\right\}$ converges strongly to $z=P_{F \cap E P} x_{0}$. By (3.58), we have $u_{n} \rightarrow z=P_{F \cap E P} x_{0}$ also. This completes the proof of Theorem 3.2.

Corollary 3.3. Let $C$ be a nonempty bounded closed convex subset of a real Hilbert space $H$, let $\phi$ : $C \times C \rightarrow R$ be a bifunction satisfying the conditions (A1)-(A4), let $\left\{S_{m}\right\}$ be a family of asymptotically nonexpansive mappings of $C$ into itself with Lipschitz constants $\left\{t_{m, n}\right\}$, that is, $\left\|S_{m}^{n} x-S_{m}^{n} y\right\| \leq$ $t_{m, n}\|x-y\|$ (for all $m, n \in N$, for all $x, y \in C$ ) such that $F \cap E P(\phi) \neq \emptyset$, where $F:=\cap_{i=1}^{\infty} F\left(S_{i}\right)$, and let $\left\{\beta_{n, k}: n, k \in N, 1 \leq k \leq n\right\}$ be a sequence of real numbers with $0<a \leq \beta_{n, 1} \leq 1$ for all $n \in N$ and $0<b \leq \beta_{n, i} \leq c<1$ for every $n \in N$ and $i=2, \ldots, n$ for some $a, b, c \in(0,1)$. Let $W_{n}$ be the modified $W$-mapping generated by $S_{n}, S_{n-1}, \ldots, S_{1}$ and $\beta_{n, n}, \beta_{n, n-1}, \ldots, \beta_{n, 2}, \beta_{n, 1}$. Assume that 
$r_{n, k}=\left\{\beta_{n, k}\left(t_{k, n}^{2}-1\right)+\beta_{n, k} \beta_{n, k+1} t_{k, n}^{2}\left(t_{k+1, n}^{2}-1\right)+\cdots+\beta_{n, k} \beta_{n, k+1} \cdots \beta_{n, n-1} t_{k, n}^{2} t_{k+1, n}^{2} \cdots t_{n-2, n}^{2}\left(t_{n-1, n}^{2}-\right.\right.$ 1) $\left.+\beta_{n, k} \beta_{n, k+1} \cdots \beta_{n, n} t_{k, n}^{2} t_{k+1, n}^{2} \cdots t_{n-1, n}^{2}\left(t_{n, n}^{2}-1\right)\right\}$ for every $n \in N$ and $k=1,2, \ldots, n$ such that $\lim _{n \rightarrow \infty} r_{n, 1}=0$. Let $\left\{x_{n}\right\}$ and $\left\{u_{n}\right\}$ be sequences generated by the following algorithm:

$x_{0} \in C$ chosen arbitrarily,

$$
\begin{gathered}
u_{n} \in C \text { such that } \phi\left(u_{n}, y\right)+\frac{1}{r_{n}}\left\langle y-u_{n}, u_{n}-x_{n}\right\rangle \geq 0, \quad \forall y \in C, \\
y_{n}=\alpha_{n} u_{n}+\left(1-\alpha_{n}\right) W_{n} u_{n}, \\
C_{n+1}=\left\{v \in C_{n}:\left\|y_{n}-v\right\|^{2} \leq\left\|x_{n}-v\right\|^{2}+\theta_{n}\right\}, \\
x_{n+1}=P_{C_{n+1}} x_{0}, \quad n \in N \cup\{0\},
\end{gathered}
$$

where $C_{0}=C$ and $\theta_{n}=\left(1-\alpha_{n}\right) r_{n, 1}(\operatorname{diam} C)^{2}$ and $0 \leq \alpha_{n} \leq d<1$ and $\left\{r_{n}\right\} \subset(0, \infty)$ such that $\liminf _{n \rightarrow \infty} r_{n}>0$. Then $\left\{x_{n}\right\}$ and $\left\{u_{n}\right\}$ converge strongly to $P_{F \cap E P(\phi)}\left(x_{0}\right)$.

Proof. Putting $A=0$, the conclusion of Corollary 3.3 can be obtained as in the proof of Theorem 3.1.

Remark 3.4. Corollary 3.3 extends the Theorem of Tada and Takahashi [19] in the following senses:

(1) from one nonexpansive mapping to a family of infinitely asymptotically nonexpansive mappings;

(2) from computation point of view, the algorithm in Corollary 3.3 is also simpler and, more convenient to compute than the one given in [19].

Corollary 3.5. Let $C$ be a nonempty bounded closed convex subset of a real Hilbert space $H$, let $\left\{S_{m}\right\}$ be a family of asymptotically nonexpansive mappings of $C$ into itself with Lipschitz constants $\left\{t_{m, n}\right\}$, that is, $\left\|S_{m}^{n} x-S_{m}^{n} y\right\| \leq t_{m, n}\|x-y\|$ (for all $m, n \in N$, for all $x, y \in C$ ) such that $F:=\cap_{i=1}^{\infty} F\left(S_{i}\right) \neq \emptyset$, and let $\left\{\beta_{n, k}: n, k \in N, 1 \leq k \leq n\right\}$ be a sequence of real numbers with $0<a \leq \beta_{n, 1} \leq 1$ for all $n \in N$ and $0<b \leq \beta_{n, i} \leq c<1$ for every $n \in N$ and $i=2, \ldots, n$ for some $a, b, c \in(0,1)$. Let $W_{n}$ be the modified $W$-mapping generated by $S_{n}, S_{n-1}, \ldots, S_{1}$ and $\beta_{n, n}, \beta_{n, n-1}, \ldots, \beta_{n, 2}, \beta_{n, 1}$. Assume that $r_{n, k}=\left\{\beta_{n, k}\left(t_{k, n}^{2}-1\right)+\beta_{n, k} \beta_{n, k+1} t_{k, n}^{2}\left(t_{k+1, n}^{2}-1\right)+\cdots+\beta_{n, k} \beta_{n, k+1} \cdots \beta_{n, n-1} t_{k, n}^{2} t_{k+1, n}^{2} \cdots t_{n-2, n}^{2}\left(t_{n-1, n}^{2}-\right.\right.$ 1) $\left.+\beta_{n, k} \beta_{n, k+1} \cdots \beta_{n, n} t_{k, n}^{2} t_{k+1, n}^{2} \cdots t_{n-1, n}^{2}\left(t_{n, n}^{2}-1\right)\right\}$ for every $n \in N$ and $k=1,2, \ldots, n$ such that $\lim _{n \rightarrow \infty} r_{n, 1}=0$. Let $\left\{x_{n}\right\}$ be a sequence generated by the following algorithm:

$$
\begin{gathered}
x_{0} \in C \text { chosen arbitrarily, } \\
y_{n}=W_{n} x_{n}, \\
C_{n+1}=\left\{v \in C_{n}:\left\|y_{n}-v\right\|^{2} \leq\left\|x_{n}-v\right\|^{2}+\theta_{n}\right\}, \\
x_{n+1}=P_{C_{n+1}} x_{0}, n \in N \cup\{0\},
\end{gathered}
$$

where $C_{0}=C$ and $\theta_{n}=r_{n, 1}(\operatorname{diam} C)^{2}$. Then $\left\{x_{n}\right\}$ converges strongly to $P_{F}\left(x_{0}\right)$. 
Proof. Putting $\phi(x, y) \equiv 0$, for all $x, y \in C, r_{n}=1, A=0$ and $\alpha_{n}=0$, for all $n \in N$ in Theorem 3.1, we have $u_{n}=P_{C} x_{n}=x_{n}$, therefore $y_{n}=W_{n} u_{n}=W_{n} x_{n}$. The conclusion of Corollary 3.5 can be obtained from Theorem 3.1 immediately.

Remark 3.6. Corollary 3.5 extends Theorem 3.1 of Inchan and Plubtieng [16] from two asymptotically nonexpansive mappings to an infinite family of asymptotically nonexpansive mappings.

Corollary 3.7. Let $C$ be a nonempty bounded closed convex subset of a real Hilbert space $H$, and let $\left\{S_{m}\right\}$ be a family of asymptotically nonexpansive mappings of $C$ into itself with Lipschitz constants $\left\{t_{m, n}\right\}$, that is, $\left\|S_{m}^{n} x-S_{m}^{n} y\right\| \leq t_{m, n}\|x-y\|$ (for all $m, n \in N$, for all $x, y \in C$ ) such that $F:=$ $\cap_{i=1}^{\infty} F\left(S_{i}\right) \neq \emptyset$. Let $T_{n}=\sum_{k=1}^{n} \beta_{n, k} S_{k}^{n}$ for every $n \in N$, where $0 \leq \beta_{n, k} \leq 1$ for every $n=1,2,3, \ldots$ and $k=1,2, \ldots, n$ with $\sum_{k=1}^{n} \beta_{n, k}=1$ for each $n \in N$ and $\lim _{n \rightarrow \infty} \beta_{n, k}>0$ for every $k \in N$, and assume that $\gamma_{n}=\sum_{k=1}^{n} \beta_{n, k}\left(t_{k, n}^{2}-1\right)$ for every $n \in N$ such that $\lim _{n \rightarrow \infty} \gamma_{n}=0$. Let $\left\{x_{n}\right\}$ be a sequence generated by

$$
\begin{gathered}
x_{0} \in C \text { chosen arbitrarily, } \\
y_{n}=T_{n} x_{n}, \\
C_{n}=\left\{v \in C:\left\|y_{n}-v\right\|^{2} \leq\left\|x_{n}-v\right\|^{2}+\theta_{n}\right\}, \\
Q_{n}=\left\{v \in C:\left\langle x_{0}-x_{n}, x_{n}-v\right\rangle \geq 0\right\}, \\
x_{n+1}=P_{C_{n} \cap Q_{n}} x_{0}, \quad n \in N \cup\{0\},
\end{gathered}
$$

where $C_{0}=C$ and $\theta_{n}=\gamma_{n}(\operatorname{diam} C)^{2}$. Then $\left\{x_{n}\right\}$ converges strongly to $P_{F}\left(x_{0}\right)$.

Proof. Putting $\phi(x, y) \equiv 0$, for all $x, y \in C, r_{n}=1, A=0$ and $\alpha_{n}=0$, for all $n \in N$ in Theorem 3.2, we have $u_{n}=P_{C} x_{n}=x_{n}$, therefore $y_{n}=T_{n} u_{n}=T_{n} x_{n}$. The conclusion of Corollary 3.7 can be obtained from Theorem 3.2.

Remark 3.8. Corollary 3.7 extends Theorem 3.1 of Zegeye and Shahzad [18] from a finite family of asymptotically nonexpansive mappings to an infinite family of asymptotically nonexpansive mappings.

\section{Acknowledgments}

This research is supported by the National Science Foundation of China under Grant (10771175) and by the key project of chinese ministry of education (209078) and the Natural Science Foundational Committee of Hubei Province (D200722002).

\section{References}

[1] K. Goebel and W. A. Kirk, "A fixed point theorem for asymptotically nonexpansive mappings," Proceedings of the American Mathematical Society, vol. 35, pp. 171-174, 1972.

[2] P. L. Combettes and S. A. Hirstoaga, "Equilibrium programming in Hilbert spaces," Journal of Nonlinear and Convex Analysis, vol. 6, no. 1, pp. 117-136, 2005. 
[3] E. Blum and W. Oettli, "From optimization and variational inequalities to equilibrium problems," The Mathematics Student, vol. 63, no. 1-4, pp. 123-145, 1994.

[4] A. Moudafi and M. Théra, "Proximal and dynamical approaches to equilibrium problems," in IllPosed Variational Problems and Regularization Techniques, vol. 477 of Lecture Notes in Economics and Mathematical Systems, pp. 187-201, Springer, Berlin, Germany, 1999.

[5] F. E. Browder and W. V. Petryshyn, "Construction of fixed points of nonlinear mappings in Hilbert space," Journal of Mathematical Analysis and Applications, vol. 20, pp. 197-228, 1967.

[6] F. Liu and M. Z. Nashed, "Regularization of nonlinear ill-posed variational inequalities and convergence rates," Set-Valued Analysis, vol. 6, no. 4, pp. 313-344, 1998.

[7] K. Nakajo and W. Takahashi, "Strong and weak convergence theorems by an improved splitting method," Communications on Applied Nonlinear Analysis, vol. 9, no. 2, pp. 99-107, 2002.

[8] C. I. Podilchuk and R. J. Mammone, "Image recovery by convex projections using a least-squares constraint," Journal of the Optical Society of America A, vol. 7, pp. 517-521, 1990.

[9] C. Byrne, "A unified treatment of some iterative algorithms in signal processing and image reconstruction," Inverse Problems, vol. 20, no. 1, pp. 103-120, 2004.

[10] K. Nakajo, K. Shimoji, and W. Takahashi, "On strong convergence by the hybrid method for families of mappings in Hilbert spaces," Nonlinear Analysis: Theory, Methods \& Applications, vol. 71, no. 1-2, pp. 112-119, 2009.

[11] W. R. Mann, "Mean value methods in iteration," Proceedings of the American Mathematical Society, vol. 4, pp. 506-510, 1953.

[12] S. Ishikawa, "Fixed points by a new iteration method," Proceedings of the American Mathematical Society, vol. 44, pp. 147-150, 1974.

[13] K.-K. Tan and H. K. Xu, "Approximating fixed points of nonexpansive mappings by the Ishikawa iteration process," Journal of Mathematical Analysis and Applications, vol. 178, no. 2, pp. 301-308, 1993.

[14] K. Nakajo and W. Takahashi, "Strong convergence theorems for nonexpansive mappings and nonexpansive semigroups," Journal of Mathematical Analysis and Applications, vol. 279, no. 2, pp. 372 $379,2003$.

[15] T.-H. Kim and H.-K. Xu, "Strong convergence of modified Mann iterations for asymptotically nonexpansive mappings and semigroups," Nonlinear Analysis: Theory, Methods \& Applications, vol. 64, no. 5, pp. 1140-1152, 2006.

[16] I. Inchan and S. Plubtieng, "Strong convergence theorems of hybrid methods for two asymptotically nonexpansive mappings in Hilbert spaces," Nonlinear Analysis: Hybrid Systems, vol. 2, no. 4, pp. 11251135, 2008.

[17] W. Takahashi, Y. Takeuchi, and R. Kubota, "Strong convergence theorems by hybrid methods for families of nonexpansive mappings in Hilbert spaces," Journal of Mathematical Analysis and Applications, vol. 341, no. 1, pp. 276-286, 2008.

[18] H. Zegeye and N. Shahzad, "Strong convergence theorems for a finite family of asymptotically nonexpansive mappings and semigroups," Nonlinear Analysis: Theory, Methods \& Applications, vol. 69, no. 12 , pp. 4496-4503, 2008.

[19] A. Tada and W. Takahashi, "Weak and strong convergence theorems for a nonexpansive mapping and an equilibrium problem," Journal of Optimization Theory and Applications, vol. 133, no. 3, pp. 359-370, 2007.

[20] Z. Opial, "Weak convergence of the sequence of successive approximations for nonexpansive mappings," Bulletin of the American Mathematical Society, vol. 73, pp. 591-597, 1967.

[21] K. Goebel and W. A. Kirk, Topics in Metric Fixed Point Theory, vol. 28 of Cambridge Studies in Advanced Mathematics, Cambridge University Press, Cambridge, UK, 1990.

[22] W. Takahashi, Nonlinear Functional Analysis, Yokohama Publishers, Yokohama, Japan, 2000.

[23] P.-K. Lin, K.-K. Tan, and H. K. Xu, "Demiclosedness principle and asymptotic behavior for asymptotically nonexpansive mappings," Nonlinear Analysis: Theory, Methods E Applications, vol. 24, no. 6, pp. 929-946, 1995.

[24] C. Martinez-Yanes and H.-K. Xu, "Strong convergence of the CQ method for fixed point iteration processes," Nonlinear Analysis: Theory, Methods \& Applications, vol. 64, no. 11, pp. 2400-2411, 2006.

[25] W. Takahashi, "Weak and strong convergence theorems for families of nonexpansive mappings and their applications," Annales Universitatis Mariae Curie-Sklodowska. Sectio A, vol. 51, no. 2, pp. 277-292, 1997. 